\title{
Signal processing of C-RTD Sensor output as the input to the instrument of low temperature monitoring using Arduino Uno Rev.3
}

\author{
Rismawan $^{1}$, Moh. Toifur ${ }^{2}$ \\ Universitas Ahmad Dahlan \\ Jl. Dr. Soepomo, SH., Janturan, Warungboto, Umbulharjo, Yogyakarta, Indonesia. \\ Dick.aries@gmail.com
}

\begin{abstract}
The C-RTD (Coil-Resistance Temperature Detector) output signal is an analog signal in the form of a direct voltage. This value changes with changes in RTD temperature. This analog signal can be read by users using a multimeter or similar device but does not directly indicate the RTD temperature. In order to obtain RTD temperature values, an additional device is required. In order to have a useful value and practicality, a device that can convert analog signals into values can be read directly by the user. The microcontroller was chosen as a used device. The selected microcontroller system is Arduino Uno because has been coupled with input and output ports so users only need to enter programs related to the system being created. In the other hand Arduino Uno by considering the low cost and practical. For the measurement system, the RTD output signal must be conditioned into a digital signal using the ADC so that it can be processed by the microcontroller. From testing instrument obtained that the system has been able to convert analog RTD signals into digital signals. The range of measurement is $-176^{\circ} \mathrm{C}$ to $0^{\circ} \mathrm{C}$ with an accuracy of $\pm 0.20 / \mathrm{mV}$.
\end{abstract}

Keywords: ADC, Arduino Uno, calibration curve, analog signal

\section{Introduction}

Temperature is the degree of the amount of energy contained in objects [1]. The more energy contained the object, the greater the temperature. This is related to the movement of particles making up objects. The higher the energy, the more agile the movement of particles making up the object.

As energy, heat has the property of being able to move and interact with objects around it. The heat flowing through the conductive wire can cause an increase in the electrical resistance of a wire. The principle of interaction of heat energy with this object can be used to measure the amount of energy of an object. One of the uses of these properties is temperature measurement through changes in wire resistance due to changes in temperature [2].

The copper coil has been widely used as a Resistant Temperature Detector (RTD). In Riswanto's research, copper wire-based RTD has been produced which has a cross-sectional area of $0.2 \mathrm{~mm}$ cross section and 500 turns. This RTD is used to measure liquid nitrogen temperatures from 0 to $1900 \mathrm{C}$. The study also produces a relationship between voltage and temperature following secondorder polynomials, namely with values [3]. With the determination index, it can be interpreted that the error rate of the relationship between $V$ and $T$ is only $10-5 \%$ or almost no errors.

Further research conducted by Rismawan and Moh. Toifur obtained RTD output signal from copper wire with a diameter of $0.3 \mathrm{~mm}$ and a length of 5 meters which was formed into a coil. This study produces a pattern of relations between voltage and temperature in the form of polynomials

$y=A e^{-c x}+B$

Research that uses RTD as a temperature sensor needs to be continued so that it can be used for practical purposes. The calibration curves of voltage to temperature done manually need to be followed up into a system that can work automatically and practically. The system can work 24 hours and continuously. One effort that can be done is to use a microcontroller system. This system 
can be designed to work independently and continuously. With a small form and need a little extra equipment, a complete system can be made.

The microcontroller is able to process input signals from RTD to temperature values through two sequential processes. First digitizing RTD voltage analog signals. In this process, analog signals are converted into digital by the microcontroller. The next process is the conversion of digital signals from RTD to temperature values through an algorithm determined by microcontroller users [4].

The use of a microcontroller system as an analog signal processing device into a temperature value has been carried out in various fields, including sound to obtain sound intensity, light to measure the intensity emitted by light sources, measuring temperature without touching the object [5]. In this study, a microcontroller is used to process analog temperature signals into digital data then provide temperature output in the form of numerical data.

\section{Experiment Procedure}

\section{Research method}

Processing RTD signals into digital input into microcontrollers have specific characteristics. The data from signal logging show the minimum voltage is 0.5 volts and the maximum voltage is 1.876 volts. In order the signal from the RTD that has been amplified is possible to be processed by the microcontroller it is necessary to make a device with the following specifications:

- Minimum input voltage $=0$ volts

- Maximum input voltage $=2$ volts

- Operating voltage $=9$ volts (adjusted for battery)

The flow of processing an analog signal into digital is shown in Figure 1. This program needs to be systematically programmed so that the input signal can be converted into a temperature value by the microcontroller. The value of data processing can be known by streaming data that have been processed by the microcontroller through the Arduino USB port to the PC and recording the data.

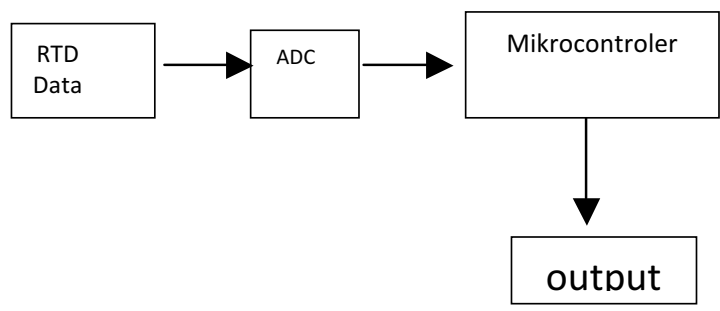

Figure 1. Flow chart of RTD data acquisition to the microcontroller

\section{Conversion analog RTD output signals to digital.}

RTD analog signals need to be converted into digital signals for further processing by microcontrollers. ADC converts analog signals into digital signals through the principle of a voltage divider. The voltage that enters the ADC will pass a voltage divider circuit and compare the value with the reference voltage. These values are then stored in registers which are then released together into data bits. The number of data bits depends on the desired resolution [6]. For measurement needs with very small voltage changes, an $\mathrm{ADC}$ with large resolution and small noise are needed. The presence of noise in small signal changes can cause incorrect readings of the ADC.

In this study, the MCP3202 ADC with 12 bits of data was used. The reference voltage used is the maximum voltage released by the signal amplifier, which is 2.7 volts. So, the selected ADC reference voltage is 2.7 volts. This is so that the ADC can change all the voltages of the RTD amplifier.

ADC conversion results follow equation (2)

bit $_{\mathrm{ADC}}=\frac{V_{A D C} * 2,7}{4095}$

\section{Linearization of exponential equations}

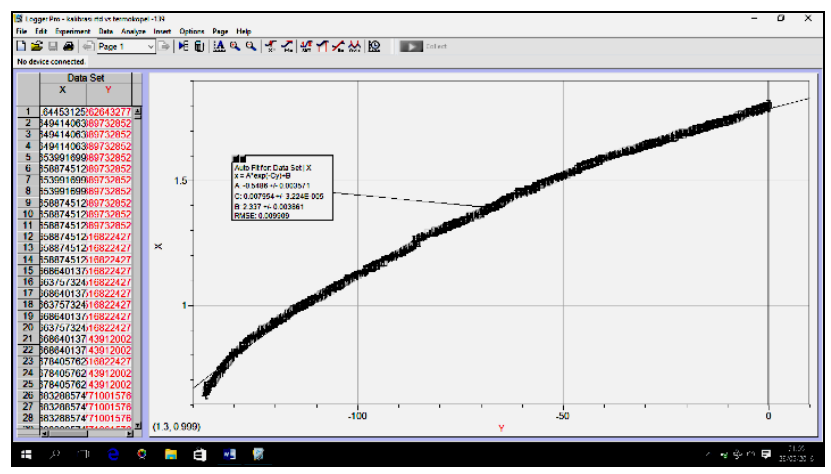

Figure 2. Calibration of Voltage curve with respect to temperature

The equation of the microcontroller input signal from RTD is a signal that satisfies the exponential curve with the shape as shown in Figure 2 so that it matches to the eq. (1). By using the curve equation that has been obtained from the previous RTD voltage measurement, we get the equation,

$y=-0,5468 e^{-0.007954 x}+2.337$ 
Where $x$ is temperature, and $y$ is voltage. This curve is a voltage curve as a function of temperature. For the purposes of processing a voltage signal into a temperature function, the equation of the curve needs to be converted into a temperature curve as a function of voltage. The equation of the curve as expressed in (1) can be processed by the temperature expressed as a function of voltage.

$$
x=\frac{-1}{c} \ln \frac{(y-B)}{A}
$$

Where each of $\mathrm{x}$ and $\mathrm{y}$ is temperatur and voltage. This curve is a voltage as a function of temperature. For the purposes of processing a voltage signal into temperature, the equation of the curve needs to be converted into a temperature curve as a function of voltage. The curve equation as expressed in (1) can process the temperature quantity into a voltage quantity.

Linearization is needed in the process of temperature measurement. By obtaining a linear relationship between voltage and temperature, the signal processing from the RTD sensor becomes simple [7]. Some sensors have a signal output that is not linear with temperature changes. Some RTDs have output signal characteristics in the form of polynomial equations. This condition makes it difficult in making the instrument.

\section{Programming of Arduino Uno}

Arduino Uno is a minimum system for develope the use of microcontroller [8]. This minimum system has been completed with an integrated development environment (IDE). This IDE can be downloaded freely through the official Arduino website. The Arduino IDE can be enriched with programming libraries or known as a library that has been developed by many communities [9]. This library makes it easy for developers to create a system that suits their needs. For the purposes of processing RTD signals, Arduino programming is needed with the path as shown in Figure 3.

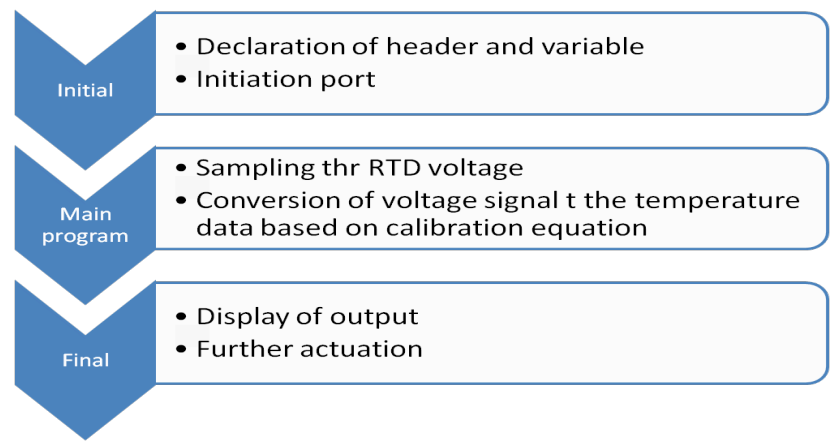

Figure 3. Flow chart of Arduino Uno programming

\section{Results and Discussion}

The use of linearization equations as given in Eq. (1) to Eq. (4) has produced by microcontroller where the output voltage is proportional to temperature. The temperature output match value of the microcontroller with the reading of the medium temperature by the RTD has a reading range of $176^{\circ} \mathrm{C}$ to $20^{\circ} \mathrm{C}$. Reliable reading values based on device calibration made with Vernier temperature probes are $-139^{\circ} \mathrm{C}$ to $0^{\circ} \mathrm{C}$. The value of the microcontroller reading for each temperature change is seen in Figure 4. The values outside the range are generated from extrapolation by the microcontroller. Extrapolation data obtained from the equation of the voltage calibration curve with respect to temperature. This can be interpreted that the processing of RTD voltage signals using a microcontroller has the advantage of being able to measure temperatures lower than those used for calibration.

The temperature produced by the microcontroller through voltage conversion by the calibration curve equation is digital data in the form of a serial. This serial data can be recorded to other devices, such as PCs and data loggers. This data can be used further for equipment control purposes or for telemetry. This opens opportunities for wide development.

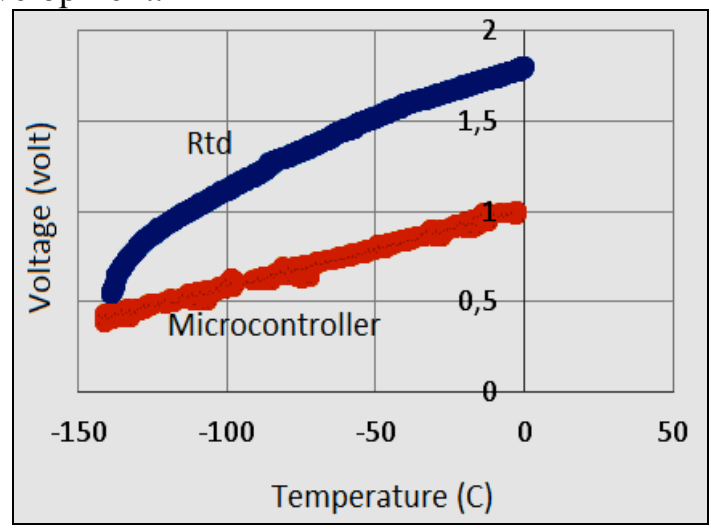

Figure 4. Comparison of RTD voltage signal and ADC processing signals

Processing signals of RTD output into digital signals for further purposes can be done with Arduino Uno revision 3. Analog signals from RTD with minimum voltage, i.e. the voltage when inserted into liquid nitrogen, is 0.5 volts, and the maximum voltage was set at $0^{\circ} \mathrm{C}$, has been successfully done. Signal processing using Arduino Uno has produced a linear voltage signal with respect to temperature. This output signal has a resolution of $0.2^{\circ} \mathrm{C} / \mathrm{mV}$ from the width value of the ADC data used. 
Signal processing of C-RTD Sensor output as the input to the instrument of low temperature monitoring...

The process of linearizing the signal equation from RTD has simplified processing by the microcontroller. This is because the microcontroller does not need to iterate to find the inverse value of the function for an input voltage value.

\section{Conclusion}

It has been successfully made a C-RTD output signal processor from voltage to numeric by utilizing Arduino Uno Rev.3 microcontroller. From the testing the equipment was obtained for temperature data from $-176^{\circ} \mathrm{C}$ to $0^{\circ} \mathrm{C}$ has an accuracy of $\pm 0.20 / \mathrm{mV}$. With this converter tool, it is possible to convert temperature data with a wider range of $-176^{\circ} \mathrm{C}$ to $0^{\circ} \mathrm{C}$ as long as that it still follows a linear relationship between voltage and temperature.

\section{Reference}

[1] Serway, R. S, and Jewett J. A, "Fisika untuk Sains dan Teknik", Jakarta: Salemba Satika, 2010

[2] Anonim, "Measuring temperatures with RTD", Natonal Instruments, Application note 046, 1996

[3] Fraden J, "Handbook of Modern Sensors: Physic, Design, and Applications",New York:Springer,1993

[4] Riswanto, "Optimasi panjang kawat dan diameter kawat tembaga sebagai piranti sensor suhu rendah berbasis 4WCB RTD”, Tesis, Yogyakarta, 2016

[5] Hendian H. Rachmat, Fuad Ughi, "Pengembangan termometer suara bagi tuna netra berbasis mikrokontroler dengan sensor suara resistif",Jurnal Rekayasa Institut Teknologi Nasional, halaman 49-59, April-Juni 2010

[6] Mccarthy, Mary, and Dillon, Eamon, "ADC Requirements for temperatures measurement systems", Analog Devices, Application note, 2006

[7] Trump, Bruce, "Analog linearization of resistances temperature detector", Texas Instruments Incorporated, 2011

[8] deSa, Douglass, "Applied Technology in Instrumentation and Process Control", New York: Taylor and Francis, 2004.

[9] Oxer J., Blemmings H., "Pratical Arduino: Cool Project for Open Source Hardware”, New York: Apress, 2009. 